EVS25

Shenzhen, China, Nov 5-9, 2010

\title{
Entering a New Stage of Learning from the U.S. Fuel Cell Electric Vehicle Demonstration Project
}

\author{
Keith Wipke ${ }^{1}$, Sam Sprik ${ }^{1}$, Jennifer Kurtz ${ }^{1}$, Todd Ramsden ${ }^{1}$, John Garbak ${ }^{2}$ \\ ${ }^{1}$ National Renewable Energy Laboratory, 1617 Cole Blvd, Golden, CO 80401, keith.wipke@nrel.gov \\ ${ }^{2}$ United States Department of Energy, 1000 Independence Ave, SW, Washington, DC, 20585, USA
}

\begin{abstract}
The National Fuel Cell Electric Vehicle Learning Demonstration is a U.S. Department of Energy (DOE) project that started in 2004. The purpose of this project is to conduct an integrated field validation that simultaneously examines the performance of fuel cell vehicles and the supporting hydrogen infrastructure. The DOE's National Renewable Energy Laboratory (NREL) has now analyzed data from over five years of the seven-year project. During this time, over 144 fuel cell electric vehicles have been deployed, and 23 project refueling stations were placed in use. We have analyzed data from over 430,000 individual vehicle trips covering 2,500,000 miles traveled and over 130,000 kg hydrogen produced or dispensed. During 2010, two of the four project teams will be concluding their involvement in the project, and the other two are continuing. Thus we will be able to focus our analysis efforts on a smaller number of vehicles and stations and enter into a new stage of learning for this project. This will allow us to dig deeper into the data to provide additional technical value to the two remaining teams as they improve their systems' technical performance in preparation for pre-commercial launch of larger fleets of vehicles in California and New York. It will also give us an opportunity to gather data and analyze performance of improved vehicles compared to those that have been previously demonstrated, since these vehicles are one step closer to commercially available customer vehicles.
\end{abstract}

Keywords: fuel cell electric vehicle, demonstration, fuel cell degradation, hydrogen fueling infrastructure

\section{Introduction}

This paper discusses key results based on data through December 2009 from the U.S. Department of Energy's (DOE's) Controlled Hydrogen Fleet and Infrastructure Validation and Demonstration Project, also referred to as the National Fuel Cell Electric Vehicle (FCEV) Learning Demonstration. NREL has now analyzed data from over five years of the sevenyear project. During this time, 144 vehicles were deployed, 23 project refueling stations were placed in use, and no fundamental safety barriers were identified. We have analyzed data from over 436,000 individual vehicle trips covering $2,500,000$ miles traveled and over $130,000 \mathrm{~kg}$ hydrogen produced or dispensed. Key objectives of the project are to evaluate fuel cell durability, vehicle driving range, and on-site hydrogen production cost. This evaluation is performed through validating the use of FCEVs and hydrogen refueling infrastructure under real-world conditions using multiple sites, various climates, 
and a variety of hydrogen sources. Fig. 1 shows photographs of the first- and second-generation vehicles and the structure of the industry teams providing NREL data.

This report also marks a transition with the makeup of the industry participants who initiated the project in 2004. The project started with four automotive original equipment manufacturers $(\mathrm{OEM})$ and energy partner teams. Since that time, DOE's California Hydrogen Infrastructure Project executed by Air Products began providing data, and additional hydrogen fueling infrastructure is being installed in California under state and local funding that will also be providing data to NREL. We have also seen completion of the project for two of the four original OEM and energy partner teams, who provided their last data by early 2010 . New analytical results generated after this report will need to be different, given the fact that there are only two automotive companies now providing data, and their sensitive data still need to be protected. Therefore, while this paper is not a final paper for the project, it is potentially the last paper to provide new commentary on the data involving all four automotive OEM teams up to December 2009. Previous comprehensive progress reports were published in July 2007 [1], November 2007 [2], and April 2008 [3], and another one will be published in August 2010.

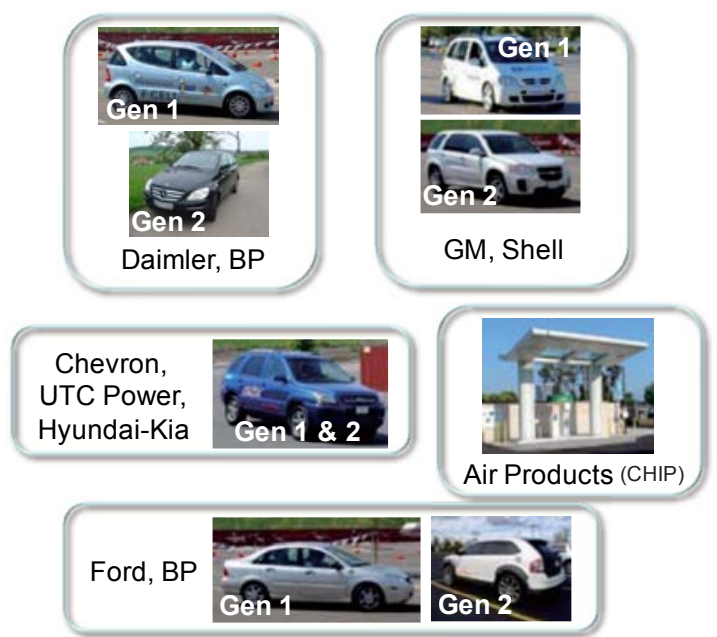

Figure 1: Photographs of the industry partners providing data to NREL on hydrogen fuel cell electric vehicles and fueling infrastructure (Photo credit: Keith Wipke)
The three high-level objectives of this project are to validate hydrogen FCEVs and infrastructure against the following targets:

- 250-mile range

- 2,000-hour fuel cell durability

- $\$ 3 /$ gge hydrogen production cost (based on volume production).

NREL works to provide the DOE and industry with maximum value from the data produced by this "learning demonstration." We seek to understand the progress toward the technical targets, and provide that information to the Fuel Cell Technologies program research and development (R\&D) activities. This information will allow the program to move more quickly toward cost-effective, reliable hydrogen FCEVs and the supporting fueling infrastructure.

\subsection{Approach}

NREL's approach to accomplishing the project's objectives is structured around a highly collaborative relationship with each of the industry teams: Chevron/Hyundai-Kia, Daimler/BP, Ford/BP, GM/Shell, and Air Products. We are receiving raw technical data on both the hydrogen vehicles and the fueling infrastructure that allows us to perform unique and valuable analyses across all teams. Our primary objectives are to feed the current technical challenges and opportunities back into the DOE Fuel Cell Technologies Program and assess the current status and progress toward targets.

To protect the commercial value of these data for each company, we established the Hydrogen Secure Data Center (HSDC) at NREL to house the data and perform our analysis. To ensure value is fed back to the hydrogen community, we publish composite data products (CDPs) twice a year at technical conferences. These data products report on the progress of the technology and the project, focusing on the most significant results. Additional CDPs are developed as additional trends and results of interest are identified. We also provide our detailed analytical results from each individual company's data back to them to maximize the industry benefit from NREL's analytical work and obtain feedback on our methodologies. These individual company results are not made available to the public.

In order to be able to evaluate such a large data set, NREL developed an in-house tool called the Fleet 


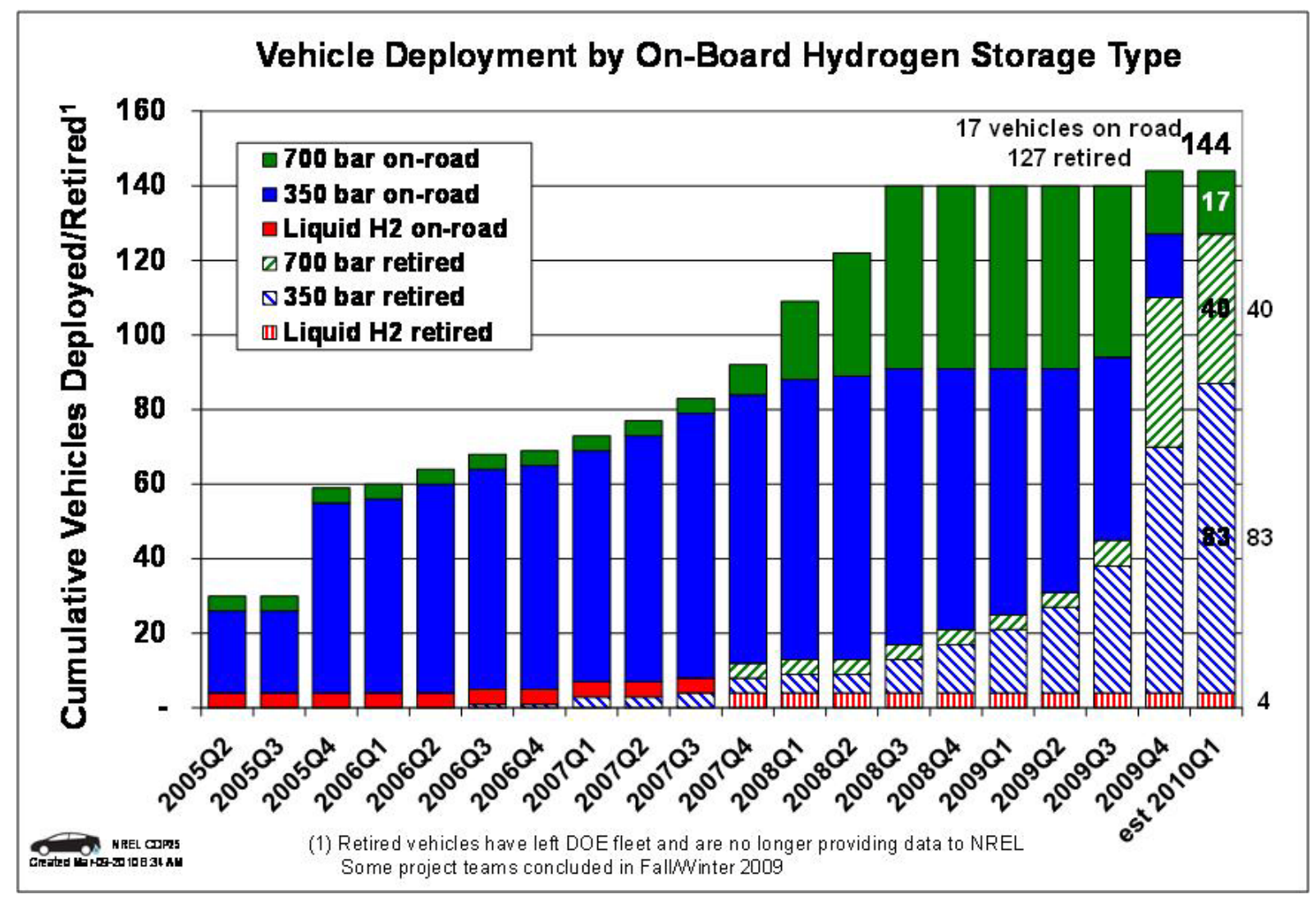

Figure 2: Cumulative number of vehicles deployed, by hydrogen storage type and status

Analysis Toolkit (NRELFAT), which helped organize and automate the various analyses being performed on both the vehicles and the infrastructure. The tool has recently undergone a major rework to allow the analysis functions to be applied not only to FCEVs, but also to fuel cell buses, fuel cell forklifts, laboratory fuel cells, backup fuel cells, stationary fuel cells, and plugin hybrid vehicles. The overall functionality of the NRELFAT has been covered in previous publications, so it will not be discussed in detail here. Having such a sophisticated tool in-house allowed us to rapidly respond to the DOE's and the U.S. Department of Defense's needs for evaluation of early market fuel cell applications.

\section{Demonstration Status}

Industry teams were selected by DOE for this project in April 2004. The first data started flowing to NREL in September 2004 after DOE had signed cooperative agreements with the industry partners. Since that time data has been flowing continuously to NREL on a monthly or quarterly basis from the teams. The project was originally scheduled to be completed in September 2008, but was extended through September 2009. Two of the teams, Ford/BP and Chevron/Hyundai$\mathrm{Kia}$, completed their projects as scheduled in September 2009, while two other teams led by Daimler and GM continued beyond that time with a new scheduled completion date of September 2011. Forty vehicles will be evaluated in the final portion of this project to track performance improvements from the latest technology. By the end of the project, it is anticipated that a cumulative total of 170 vehicles will have been evaluated.

This transition is reflected in some of the CDPs, which show the number and status of the FCEVs. As shown in Fig. 2, there were a gradual number of vehicles retired through 2008 (approximately 20 vehicles), with a much larger number retired by the fourth quarter of 2009, when two teams completed their projects. Note that all of the first-generation vehicles utilizing 350-bar pressurized hydrogen storage or liquid hydrogen have been retired, and only 700-bar storage vehicles continue to operate. 
The cumulative number of fueling stations deployed through this project is 23 . Of those 23 , as of December 2009, 8 have been decommissioned, 10 are continuing operation outside of the project, and 5 are continuing within the project. However, several of the 10 that are shown as continuing outside of the project are expected to be decommissioned in 2010. Stations demonstrated four major technologies: 1) onsite hydrogen through natural gas reformation, 2) onsite production through water electrolysis, 3) delivered liquid hydrogen, and 4) delivered compressed gas hydrogen. The highest number of stations used delivered compressed hydrogen, followed by on-site electrolysis. Over half of the electrolysis stations have been retired, whereas only one of the five on-site natural gas reformation stations has been retired.

While many of the project stations may come to the end of their useful demonstration life in the next few years, many new or upgraded stations are being opened in California as a result of the combined efforts of the California Air Resources Board, the California Energy Commission, and the South Coast Air Quality Management District. These new stations are helping provide a bridge from the early demonstration stations (from this project and other demonstrations) to a point in the future when the number of FCEVs is large enough to create a market pull for private sector investment.

In order to obtain a variety of data, the project included geographically diverse locations for demonstration of the vehicles and infrastructure. Initially, there were five regions of the country involved, including the San Francisco Bay area, the Los Angeles area, the Detroit area, Orlando, and a corridor from Washington, DC, to New York. In the last year, as two of the teams completed their portions of the project, some of the stations have been decommissioned, including all of the stations in Florida. As of August 2010, our database indicates that there are a total of 58 operational hydrogen fueling stations in the United States.

\section{Key Project Results Compared to Objectives}

Key objectives of the project are to evaluate fuel cell durability, vehicle driving range, and on-site hydrogen production cost. Progress towards these objectives will be briefly highlighted in the following subsections.

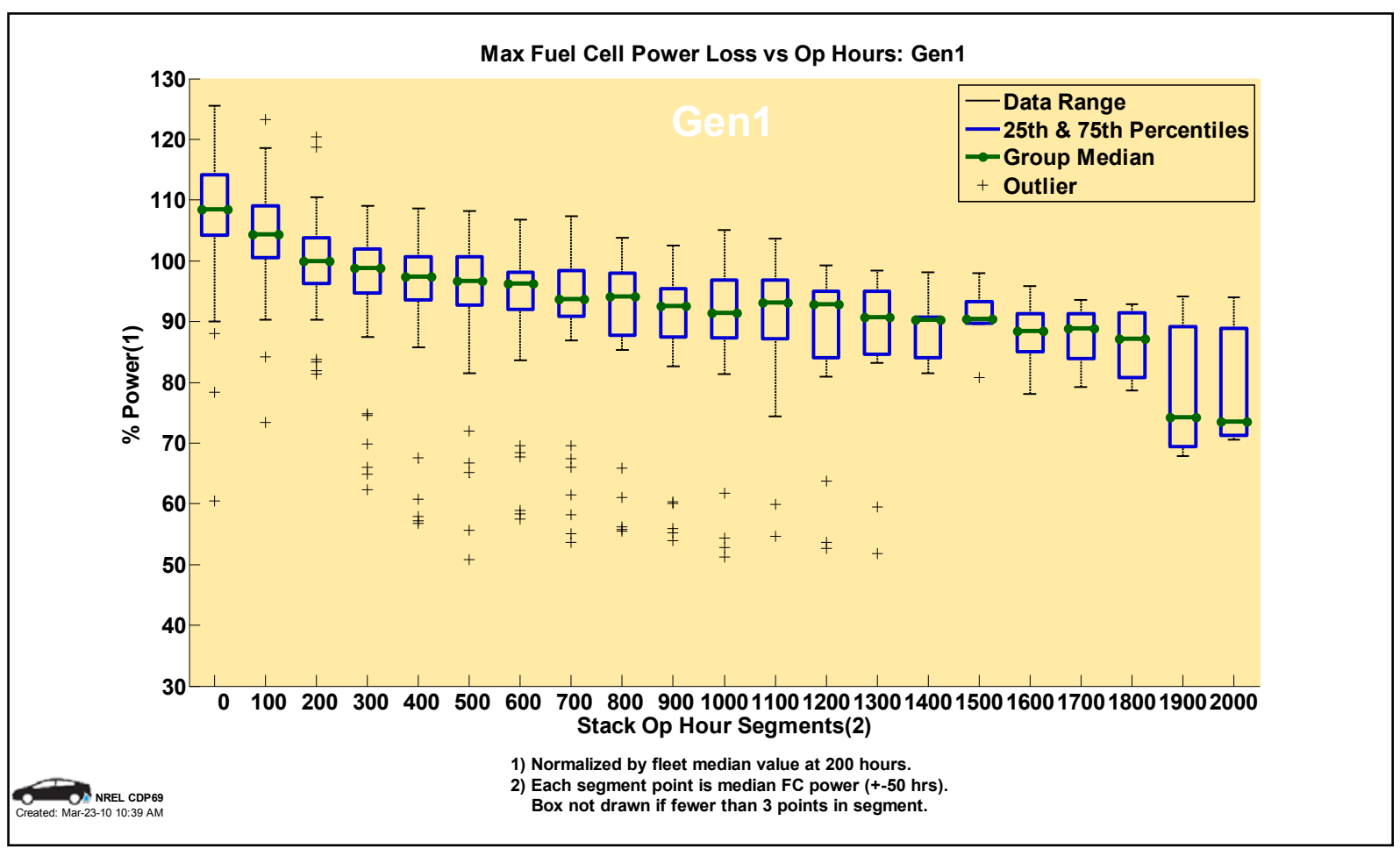

Figure 3: Maximum fuel cell power degradation, Gen 1 stacks 


\subsection{Fuel Cell Stack Durability}

Many improvements have been made in NREL's fuel cell durability analysis methodology, including using a two-segment linear fit and using a weighting algorithm to come up with a more robust and automatic fleet average. Now that the data submissions are complete on firstgeneration stacks (no new first-generation stack data is being received), we can make some final conclusions about that generation of technology. The maximum number of hours a first-generation stack accumulated without repair is 2,375 , which is the longest stack durability from a light-duty FCEV in normal use published to date that we are aware of. On average, the slope of the initial power degradation is steeper in the first 200 hours and becomes more gradual after that (Fig. 3). We also found that around 1,000 hours of data were required to reliably determine the slope of the more gradual secondary degradation. Finally, with significant drops in power observed at 1,900-2,000 hours, it appears as though this is a solid upper bound on first-generation stack durability (characterizing 2003-2005 technology).

For second-generation fuel cell stacks (20052007 technology), the range of maximum hours accumulated from the four teams is now approximately 800 to over 1,200 hours (Fig. 4), with the range of team average hours accumulated of approximately 300 to 1,100 hours. Relative to projected durability, the Spring 2010 results indicate that the highest average projected team time to $10 \%$ voltage degradation for secondgeneration systems was 2,521 hours, with a multiteam average projection of 1,062 hours. Therefore, the 2,000-hour target for durability has been validated.

\subsection{Vehicle Driving Range}

In FY 2008, the driving range of the project's FCEVs was evaluated based on fuel economy from dynamometer testing (EPA adjusted) and on-board hydrogen storage amounts and compared to the 250-mile target. The resulting second-generation vehicle driving range was between 196 and 254 miles from the four teams and met the 250-mile range objective. In June 2009, an on-road driving range evaluation was performed by NREL in collaboration with Toyota and Savannah River National Laboratory. The results indicated a 431mile on-road range was possible in southern California using Toyota's FCHV-adv fuel cell vehicle [4] (Table 1).

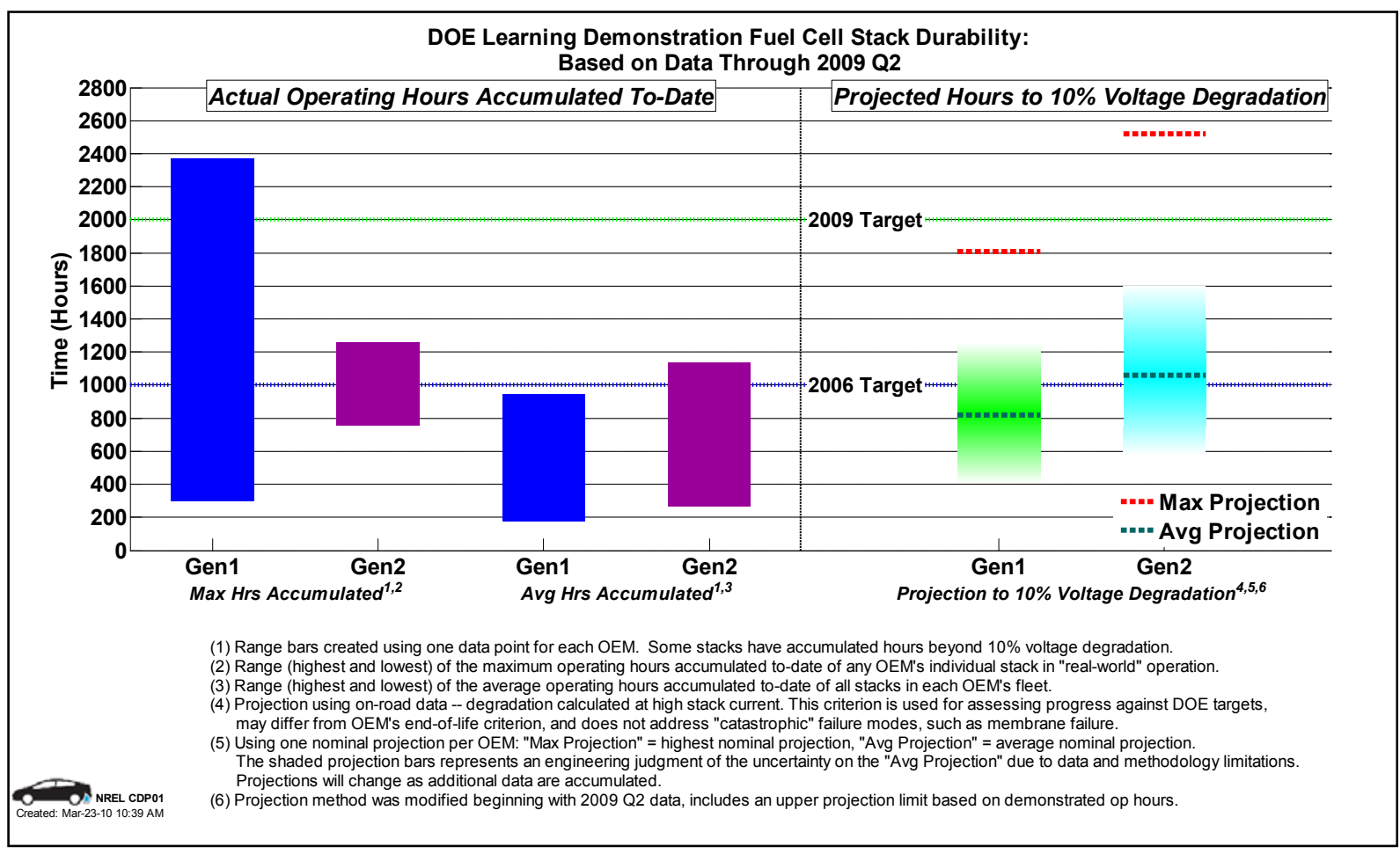

Figure 4: Hours accumulated and projected hours to $10 \%$ stack voltage degradation 
Table 1: Toyota range analysis intermediate values and final results

\begin{tabular}{lcc}
\hline & Vehicle 1 & Vehicle 2 \\
\hline Trip dist. (miles) & 331.50 & 331.45 \\
$\mathrm{H}_{2}$ used (kg) & 4.826 & 4.875 \\
Remain usable $\mathrm{H}_{2}(\mathrm{~kg})$ & 1.4854 & 1.4328 \\
Calc. remain range (miles) & 102.04 & 97.41 \\
Total range (miles) & 433.55 & 428.87 \\
Avg total range (miles) & \multicolumn{2}{c}{$\mathbf{4 3 1}$} \\
\hline
\end{tabular}

More recently, the significant on-road data that have been obtained from second- and firstgeneration vehicles allowed a comparison of the real-world driving ranges of all the vehicles in the project. The data show that there has been a $45 \%$ improvement in the median real-world driving range of second-generation vehicles ( 81 miles) as compared to first-generation (56 miles), based on actual distances driven between over 25,000 refueling events (Fig. 5). Obviously the vehicles are capable of two to three times greater range than this, but the median distance travelled between refuelings is one way to measure the improvement in the vehicles' capability and the way in which they are actually being driven.

\subsection{Onsite Hydrogen Production Cost}

Cost estimates from the Learning Demonstration energy company partners were used as input to an $\mathrm{H} 2 \mathrm{~A}$ analysis to project the hydrogen cost for $1,500 \mathrm{~kg} /$ day early market fueling stations $(\mathrm{H} 2 \mathrm{~A}$ is DOE's suite of hydrogen analysis tools, with the H2A Production model focused on calculating the costs of producing hydrogen). Results indicate that on-site natural gas reformation could lead to a price range of $\$ 8-\$ 10 / \mathrm{kg}$, and on-site electrolysis could lead to a range of $\$ 10-\$ 13 / \mathrm{kg}$ hydrogen cost. While these results do not achieve the $\$ 3 /$ gge cost target, two external independent review panels commissioned by DOE concluded that distributed natural gas reformation could lead to a price range of $\$ 2.75-\$ 3.50 / \mathrm{kg}$ [5] and distributed electrolysis could lead to a price range of $\$ 4.90-\$ 5.70 / \mathrm{kg}$ [6]. Therefore, this objective was satisfied outside of the Learning Demonstration project.

\subsection{Overall Performance Summary}

We have summarized the previously discussed key performance numbers, along with other metrics of interest such as fuel economy and fuel cell efficiency, and compared them to DOE targets in Table 2. This table shows that this project has exceeded the expectations established in 2003 by DOE, with all of the key targets being achieved except for on-site hydrogen production cost, which would have been difficult to demonstrate through this project. Additional data accumulated and

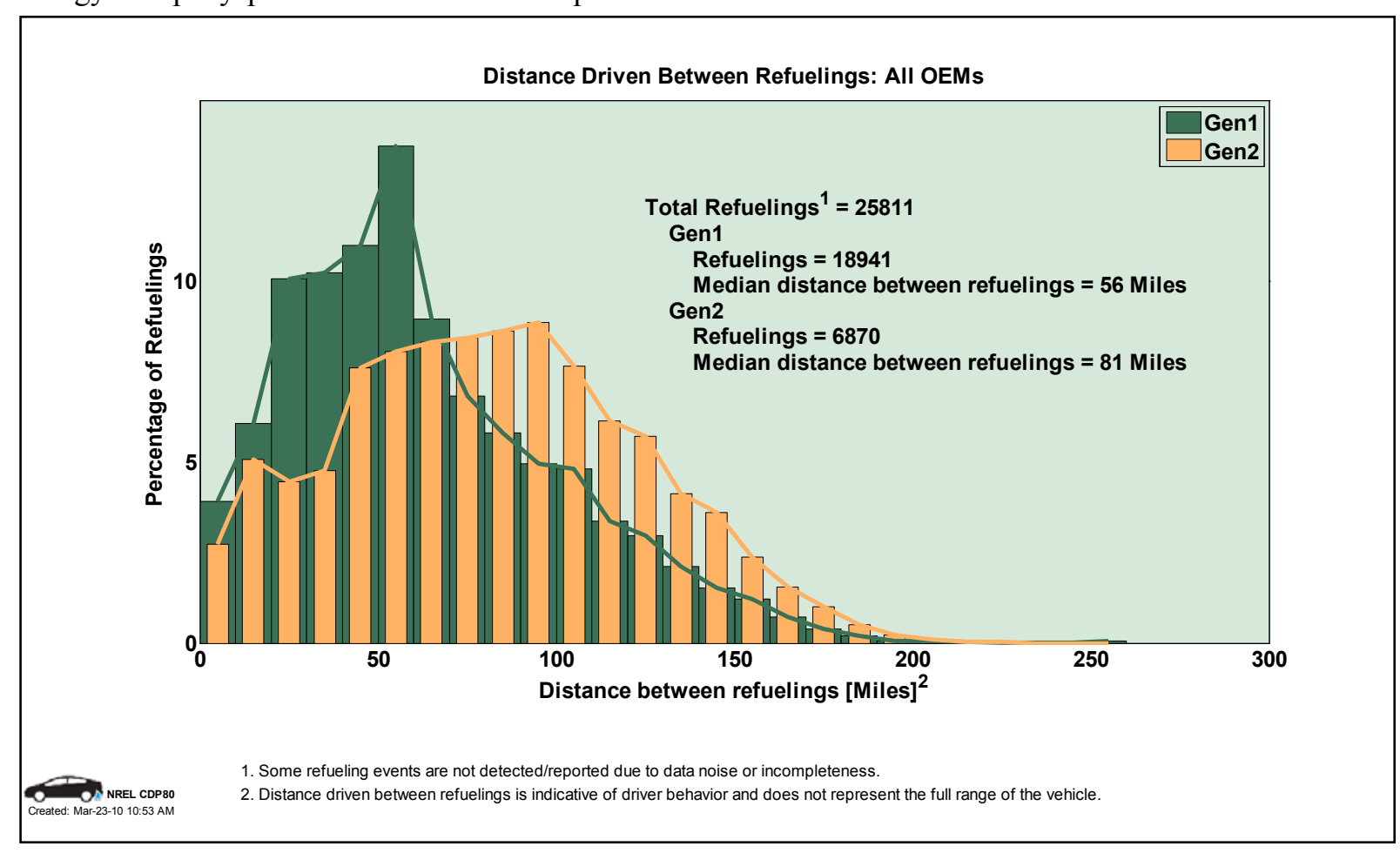

Figure 5: Actual miles between refuelings, comparing Gen 1 (green) with Gen 2 (orange) 
Table 2: Learning Demonstration key performance metrics summary

\begin{tabular}{|c|c|c|c|}
\hline Vehicle Performance Metrics & Gen 1 Vehicle & Gen 2 Vehicle & 2009 Target \\
\hline Fuel Cell Stack Durability & & & 2,000 hours \\
\hline $\begin{array}{r}\text { Max Team Projected Hours to } \\
10 \% \text { Voltage Degradation }\end{array}$ & 1,807 hours & $\underline{2,521}$ hours & \\
\hline Average Fuel Cell Durability Projection & 821 hours & 1,062 hours & \\
\hline $\begin{array}{l}\text { Max Hours of Operation } \\
\text { by a Single FC Stack to Date }\end{array}$ & 2,375 hours & 1,261 hours & \\
\hline Driving Range & $103-190$ miles & 196-254 miles & 250 miles \\
\hline FuelEconomy(Window Sticker) & $42-57 \mathrm{mi} / \mathrm{kg}$ & $43-58 \mathrm{mi} / \mathrm{kg}$ & no target \\
\hline Fuel Cell Efficiency at $1 / 4$ Power & $51-58 \%$ & $53-\underline{59} \%$ & $60 \%$ \\
\hline Fuel Cell Efficiency at Full Power & $30-54 \%$ & $42-\underline{53} \%$ & $50 \%$ \\
\hline \multicolumn{3}{|l|}{ Infrastructure Performance Metrics } & 2009 Target \\
\hline $\mathrm{H}_{2}$ Cost at Station (early market)* & $\begin{array}{l}\text { On-site natural gas } \\
\text { reformation } \\
\$ 7.70-\$ 10.30\end{array}$ & $\begin{array}{c}\text { On-site } \\
\text { Electrolysis } \\
\mathbf{\$ 1 0 . 0 0 - \$ 1 2 . 9 0}\end{array}$ & \$3/gge \\
\hline Average $\mathrm{H}_{2}$ Fueling Rate & \multicolumn{2}{|c|}{$0.77 \mathrm{~kg} / \mathrm{min}$} & $1.0 \mathrm{~kg} / \mathrm{min}$ \\
\hline \multicolumn{3}{|c|}{\begin{tabular}{|l}
${ }^{*}$ Outside of this project, DOE independent panels concluded at 500 replicate stations/year: \\
Distributed natural gas reformation at $1500 \mathrm{~kg} / \mathrm{day}: \$ 2.75-\$ 3.50 / \mathrm{kg}(2006)$ \\
Distributed electrolysis at $1500 \mathrm{~kg} / \mathrm{day}: \$ 4.90-\$ 5.70(2009)$
\end{tabular}} & \\
\hline
\end{tabular}

analyzed in $2010-2012$ will assess the latest generations of FCEV technology, which include improvements over the second-generation systems analyzed in the results to date. Future assessments will also include data analysis from many new hydrogen stations being commissioned in California, all of which will have 700-bar fueling capability.

\section{Other Vehicle Results}

\subsection{Fuel Cell System Efficiency}

Researchers from the car companies measured fuel cell system efficiency from select vehicles on a vehicle chassis dynamometer at several steady-state points of operation. NREL worked with the data and the companies to ensure that appropriate balance-of-plant electrical loads were included. This ensured that the results were comparable to the target and based on the entire system rather than just the stack. DOE's technical target for net system efficiency at onequarter power is $60 \%$. Baseline data from the four Learning Demonstration teams several years ago showed a range of net system efficiency from $51 \%$ to $58 \%$ for first-generation systems, which was very close to the target. As second- generation vehicles were introduced, the companies also performed baseline dynamometer testing that revealed an efficiency of $53 \%$ to $59 \%$ at one-quarter power, within one percentage point of the target (Fig. 6). We have expanded this CDP to include a comparison of the efficiency at full power, where DOE's target was 50\% net system efficiency. The data show first-generation systems as having $30 \%$ to $54 \%$ efficiency at full power while second-generation systems have $42 \%$ to 53 $\%$ efficiency, exceeding the $50 \%$ target.

\subsection{Voltage Transients}

In discussions with fuel cell researchers, the voltage cycling of the stack was identified as something that would be worth the team investigating further. Prior to this, only the amount of time spent at different voltages was evaluated, and not the rate of change of the voltage or the number of times the voltage changed. Our overall approach was to 1) define a voltage transient cycle, 2) find voltage transient cycles in the on-road stack data, and 3) categorize and collect voltage transient cycle details.

We found a relatively symmetric distribution of the magnitude of voltage change about 0 , with most of the cycles lasting less than 15 seconds. 


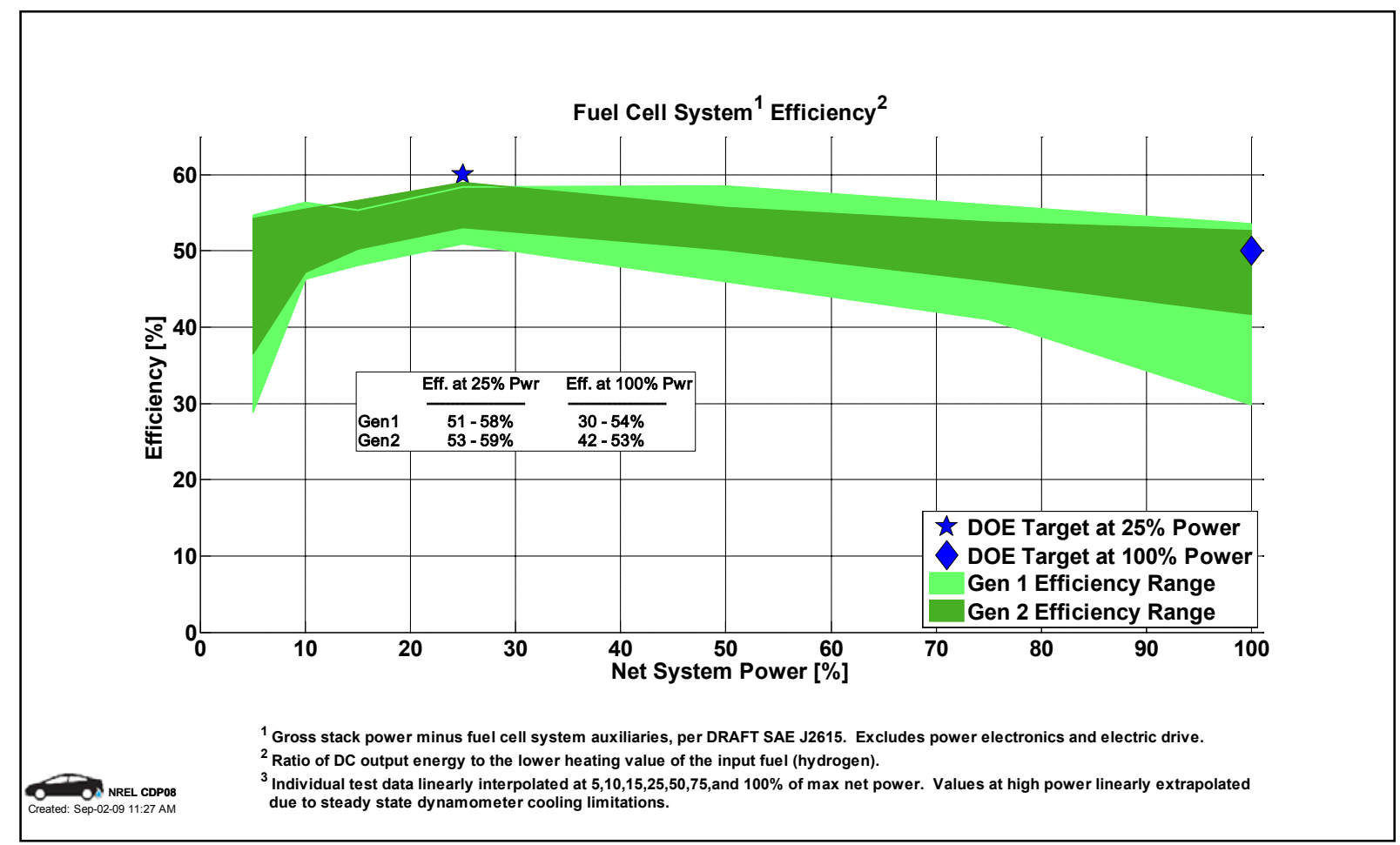

Figure 6: Fuel cell system efficiency, comparing Gen 1 and Gen 2

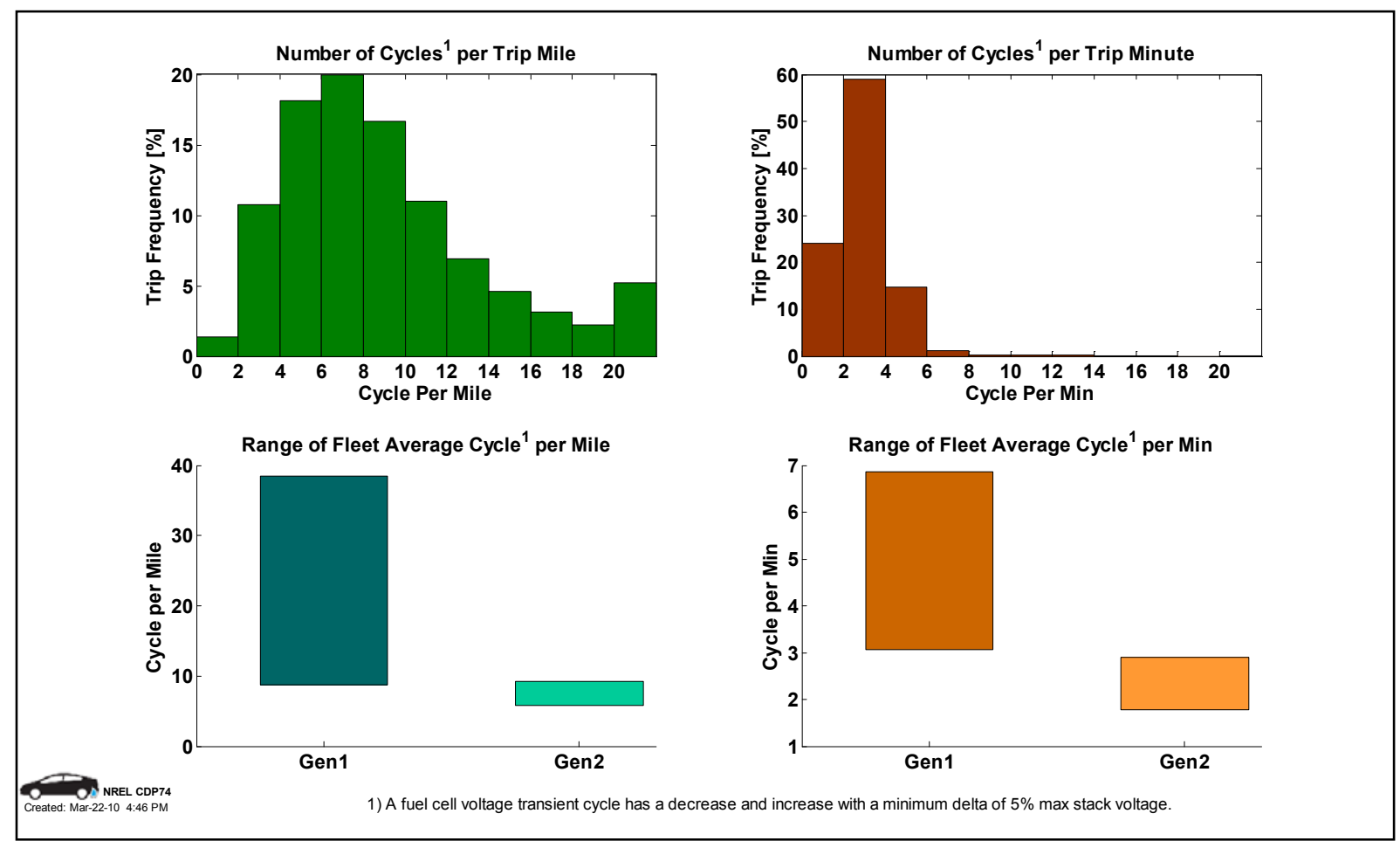

Figure 7: Fuel cell voltage transients, comparing Gen 1 and Gen 2

Once we had the voltage cycles characterized, the first thing we noticed was that the number of cycles per trip mile (and per trip minute) was drastically reduced between Gen 1 and Gen 2 for 
at least one team by a factor of 4 (lower left portion of Fig. 7). We found that the dominant transient cycle category was a "slow down, fast up" category, which was a slow voltage drop followed by a fast voltage rise. This could come from a gradual acceleration of the FCEV, followed by taking the foot off the accelerator pedal due to traffic at a stop sign or light. The frequency of each of these five cycle categories is now available to us as a new input to our multivariate analysis. We also examined the number of the voltage cycles that were outside of a threshold between $70 \%$ and $90 \%$ of maximum stack voltage. We found that these more extreme voltage transients occurred on average less than twice per mile (accounting for about one-quarter of all voltage transients), with the drop below $70 \%$ maximum stack voltage occurring more times per mile than the rise above $90 \%$ maximum stack voltage.

\subsection{Fuel Cell System Power Density and Specific Power}

DOE's target for fuel cell system power density in 2010 and 2015 is $650 \mathrm{~W} / \mathrm{L}$ and for fuel cell system specific power is $650 \mathrm{~W} / \mathrm{kg}$. System level data were gathered from the fuel cell teams and aggregated into ranges for first- and secondgeneration systems separately. First-generation fuel cell systems had a specific power of 183 to $323 \mathrm{~W} / \mathrm{kg}$, while second-generation systems improved to a range of 306 to $406 \mathrm{~W} / \mathrm{kg}$. Fuel cell system power density, on the other hand, stayed the same or dropped slightly (staying in the range of 300 to $400 \mathrm{~W} / \mathrm{L}$ ), perhaps because the Gen 2 systems had more balance of plant in order to support the freeze tolerance required.

Because of the attention that plug-in hybrid vehicles were getting, we were asked to generate fuel cell system power density and specific power results that also included the hydrogen storage, and then compare the results to the FreedomCAR targets. We found that while Gen 1 to Gen 2 showed significant progress, the 178 to $261 \mathrm{~W} / \mathrm{kg}$ was still shy of the $325 \mathrm{~W} / \mathrm{kg}$ FreedomCAR research goal when the hydrogen storage system was included. The fuel cell system power density, when the hydrogen storage was included, came extremely close (with both Gen 1 and Gen 2) to satisfying the 2010 and 2015 FreedomCAR research goal of $220 \mathrm{~W} / \mathrm{L}$ (Gen 1 was 152 to $214 \mathrm{~W} / \mathrm{L}$, and Gen 2 was 127 to $213 \mathrm{~W} / \mathrm{L}$ ). This indicates that fuel cell systems are a relatively compact means of storing both energy and power relative to batteries.

\section{Infrastructure Results - Fueling Rates}

Hydrogen vehicle refueling needs to be as similar as possible to conventional vehicle refueling to allow an easier commercial market introduction. Over 25,000 refueling events have been analyzed to date, and the refueling amount, time, and rate have been quantified. The average time to refuel was 3.26 minutes with $86 \%$ of the refueling events taking less than 5 minutes. The average amount per fill was $2.13 \mathrm{~kg}$, reflecting both the limited storage capacity of these vehicles (approximately 4 $\mathrm{kg}$ maximum) and peoples' comfort level with letting the fuel gauge get close to empty (shown in previous papers). DOE's initial target refueling rate is $1 \mathrm{~kg} / \mathrm{min}$, and these Learning Demonstration results indicate an average of $0.77 \mathrm{~kg} / \mathrm{min}$, with $23 \%$ of the refueling events exceeding $1 \mathrm{~kg} /$ minute (Fig. 8). Therefore, we can conclude that highpressure gases are approaching adequate refueling times and rates for consumers; however, the challenge is still in packaging enough highpressure hydrogen onboard to provide adequate range or finding alternate advanced hydrogen storage materials that can replace the need for high-pressure tanks.

The refueling histogram in Fig. 8 includes all types of refueling events. There has been much interest from industry and from the codes and standards community about the potential for communication fills to occur at a higher rate and with a more complete fill. A communication fill means that the vehicle communicates data about the state of its hydrogen storage tank(s) to the refueling station, such as tank temperature, pressure, and max pressure rating. The average fill rate for all communication fills is $0.86 \mathrm{~kg} / \mathrm{min}$ vs. $0.66 \mathrm{~kg} / \mathrm{min}$ for non-communication fills, with $30 \%$ and $12 \%$, respectively, exceeding DOE's $1 \mathrm{~kg} / \mathrm{min}$ target. We can thus conclude that communication fills in this project are, on average, faster than noncommunication fills.

Another partition of the fueling rate data we performed was by the storage system employed by each vehicle, comparing the fueling rate for 350 bar and 700-bar fills. Two major conclusions can be drawn from the results. The first is that the project has experienced many more 350-bar fills $(19,659)$ than 700 -bar fills $(5,590)$, since the 700 bar fuelings mainly began with the second- 


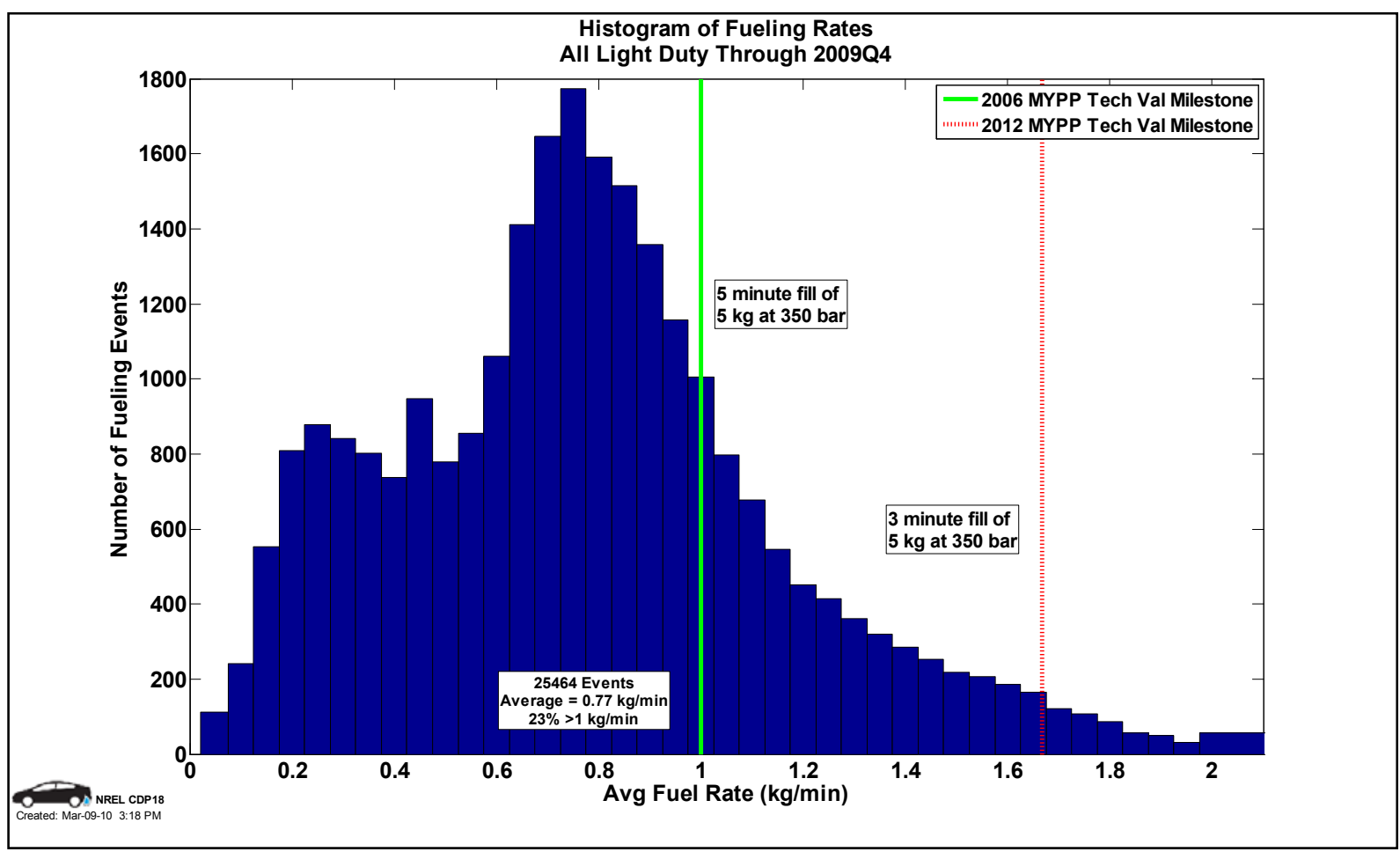

Figure 8: Fueling rates for over 25,000 events, all types included

generation vehicles halfway through the project. The second is that the fueling rate for the higher pressure fills is still slower than the lower pressure fills, with $29 \%$ of the 350-bar fills exceeding $1 \mathrm{~kg} / \mathrm{min}$ and only $4 \%$ of the 700 -bar fills exceeding the target. The average fill rate for 350 -bar fills is $0.82 \mathrm{~kg} / \mathrm{min}$, while the average rate for 700 -bar fills is $0.63 \mathrm{~kg} / \mathrm{min}$. This does not appear to be a limitation of the technology, as very high fill rates at 700 bar have been demonstrated in Germany and Canada, but rather a reflection of the current technology that has been deployed in this first wave of 700-bar stations in the U.S. Station data received in the coming years from the new stations in California should demonstrate the full capability of 700-bar fueling.

In the final fueling rate analysis, we have sliced the same data by year. We found the number of fueling events has increased year-to-year during each of the 5 years of the project to date. While the fueling rate initially increased from 0.66 $\mathrm{kg} / \mathrm{min}$ to $0.74 \mathrm{~kg} / \mathrm{min}$ to $0.81 \mathrm{~kg} / \mathrm{min}$, it has now settled at a value of $0.77 \mathrm{~kg} / \mathrm{min}$ for the last two years. Due to the number of automotive companies being reduced from four to two in
2010, the overall number of fueling events will decrease until the new California stations come online.

\section{Conclusions and Future Directions}

NREL has now completed the first five years of the seven-year project with 144 vehicles deployed in fleet operation, 23 project refueling stations constructed, and no major safety barriers encountered. We have analyzed data from 436,000 individual vehicle trips covering 2.5 million miles traveled and 130,000 kg hydrogen produced or dispensed. We have published 80 technical CDPs to date and made them directly accessible to the public from an NREL Web site [7]. We have summarized the key project performance numbers, along with other metrics of interest such as fuel economy and fuel cell efficiency, and compared them to DOE targets in Table 1. The table shows that this project has exceeded the expectations established in 2003 by DOE, with all of the key targets being achieved except for onsite hydrogen production cost, which would have been difficult to demonstrate through this project. 
From all of the results that we have generated, it is our conclusion that FCEVs have advanced rapidly in the last five years, and are expected to continue at this same rate of development in the next five years. There do not appear to be any major technical hurdles that the automotive companies and their suppliers cannot overcome, and they appear to have a glide-path to getting the costs down to a manageable incremental cost. We therefore expect continued progress to lead to market-ready vehicles in the 2015 timeframe. Several vehicle manufacturers will introduce thousands of vehicles to the market in that timeframe, and the hydrogen community will have its first true test of whether the technology will be embraced by the public.

Additional data accumulated and analyzed in 2010-2012 will assess the latest generations of FCEV technology, which include improvements over the second-generation systems included in the results to date. NREL will create new and updated CDPs based on data collected through June 2010 (Fall 2010 CDPs) and present results for publication in the fall. We will support the automotive manufacturers, energy companies, and state organizations in California in coordinating early infrastructure plans. We will gather and analyze data from a hydrogen fueling station in Burbank, California, which has a relatively high-rate of onsite hydrogen production from natural gas, along with many new stations that are being opened in California in the next year. Future assessments will include data analysis from many of the new hydrogen stations being commissioned in California, all of which will have 700-bar fueling capability.

NREL will continue to identify opportunities to feed findings from the project back into the DOE Vehicle Technologies and Fuel Cell Technologies programs and industry R\&D activities to maintain the project as a "learning demonstration." We will continue to gather data from FCEVs and hydrogen stations through 2011, and publish the Spring 2011 and Fall 2011 CDPs and likely one final set of results in Spring 2012. As the last expected deliverable from this project, we will write a final summary report for publication, which will both include new results from the final two years as well as reference and build on the results included in the 2010 interim progress report. All $80 \mathrm{CDPs}$ published to date are directly accessible from our Hydrogen Technology Validation Web site [7].

\section{References}

[1] K. Wipke, S. Sprik, H. Thomas, C. Welch, J. Kurtz, "Learning Demonstration Interim Progress Report-Summer 2007," NREL/TP560-41848, Golden, CO, NREL, June 2007.

[2] K. Wipke, S. Sprik, J. Kurtz, H. Thomas, "Learning Demonstration Progress ReportSeptember 2007," NREL/TP-560-42264, Golden, CO, NREL, November 2007.

[3] K. Wipke, S. Sprik, J. Kurtz, "Learning Demonstration Progress Report-Spring 2008," NREL/TP-560-42986, Golden, CO, NREL, April 2008.

[4] K. Wipke, D. Anton, S. Sprik, "Evaluation of Range Estimates for Toyota FCHV-adv Under Open Road Driving Conditions," prepared under SRNS CRADA number CR-04-003, Golden, CO, NREL, August 2009.

[5] J. Fletcher and V. Callaghan, "Evaluation Cost of Distributed Production of Hydrogen from Natural Gas - Independent Review," NREL/BK150-40382, Golden, CO, NREL, October 2006.

[6] J. Genovese, K. Harg, M. Paster, J. Turner, "Current (2009) State-of-the-Art Hydrogen Production Cost Estimate Using Water Electrolysis - Independent Review," NREL/BK6A1-46676, Golden, CO, NREL, September 2009.

[7] http://www.nrel.gov/hydrogen/ proj learning demo.html

\section{Primary Author}

Keith Wipke, Senior Engineer and Manager of Hydrogen Analysis

Mr. Wipke is a Senior Engineer and Manager of Hydrogen Analysis at the National Renewable Energy Laboratory, where he has worked in the area of advanced vehicles for

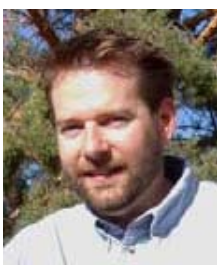
over 17 years. He has responsibility for staff working on NREL's hydrogen Technology Validation, Infrastructure Analysis, and Education activities. He received his master's degree in mechanical engineering from Stanford University. 